\title{
Construction and Strategy Research on Precise Poverty Alleviation Model of Rural E-Commerce Informationization
}

\author{
Lin Chen \\ Chengdu Agricultural College \\ Chengdu, 611130
}

\begin{abstract}
The information chain between production and consumption is broken, and the agricultural production chain is missing due to the deterioration of function for the supply and marketing cooperatives that work as a bridge. This work made a detailed explanation of the strategy for rural e-commerce informatization, innovated the rural e-commerce reconstruction mode of agricultural production chain based on information technology, and constructed the "Internet Plus" rural e-commerce information model. This work also expounded the methods of transforming farmers from networking to new-type information farmers, and developed rural e-commerce information development around the "four streams" of e-commerce.
\end{abstract}

Keywords-Information technology; Rural e-commerce; Information model

\section{RURAL E-COMMERCE RECONSTRUCTION OF AgRiCUlTURAL PRODUCTION CHAIN BASED ON INFORMATION TECHNOLOGY}

From the perspective of the agricultural production chain, it is mainly divided into four main links: production and sales of agricultural production materials, agricultural production, storage and processing of agricultural products, and sales of agricultural products. In the traditional agricultural production chain, it corresponds to the main roles of agricultural companies, supply and marketing cooperatives, farmers, agricultural enterprises and agricultural products trading domestic company [1]. With the development of urbanization, there are many problems in the first and second-tier cities, such as the gradual lack of service objects in supply and marketing cooperatives, the lack of supply objects in agricultural production materials, the transformation of rural land into urban land, and the gradual loss of traditional sales channels in agricultural products. Supply and marketing cooperatives are difficult to play the role of giving orders and material circulation, and their scale is seriously reduced. Taking Chengdu as an example, the supply and marketing cooperatives in the original main urban area (six urban areas) only have Wuhou District and Jinniu District at present, which are mainly engaged in the liquidation of assets treatment [2].

In recent years, the function of supply and marketing cooperatives, which play a bridge role, has degraded. The information chain between production and consumption has broken, and the situation of blind cultivation and dumb cultivation is common. The local government dredges the sales of products through various channels; one of the main sales channels is to push information to consumer terminals through the multi-level e-commerce platform, Weixin and Weibo official account. Although this approach can solve the urgent needs for a while, it can't solve the problem from the root cause. Therefore, considering the rural e-commerce reconstruction of the whole industrial chain based on information technology, the roles of the industrial chain are repositioned, and the differentiated production and precision sowing under big data's analysis, the accurate production under the supervision of the agricultural IOT, the commercial circulation of material supply, the exchange of information and the monitoring of logistics under the management of agricultural e-commerce platform are realized. 
Agricultural informationization

Agricultural production chain

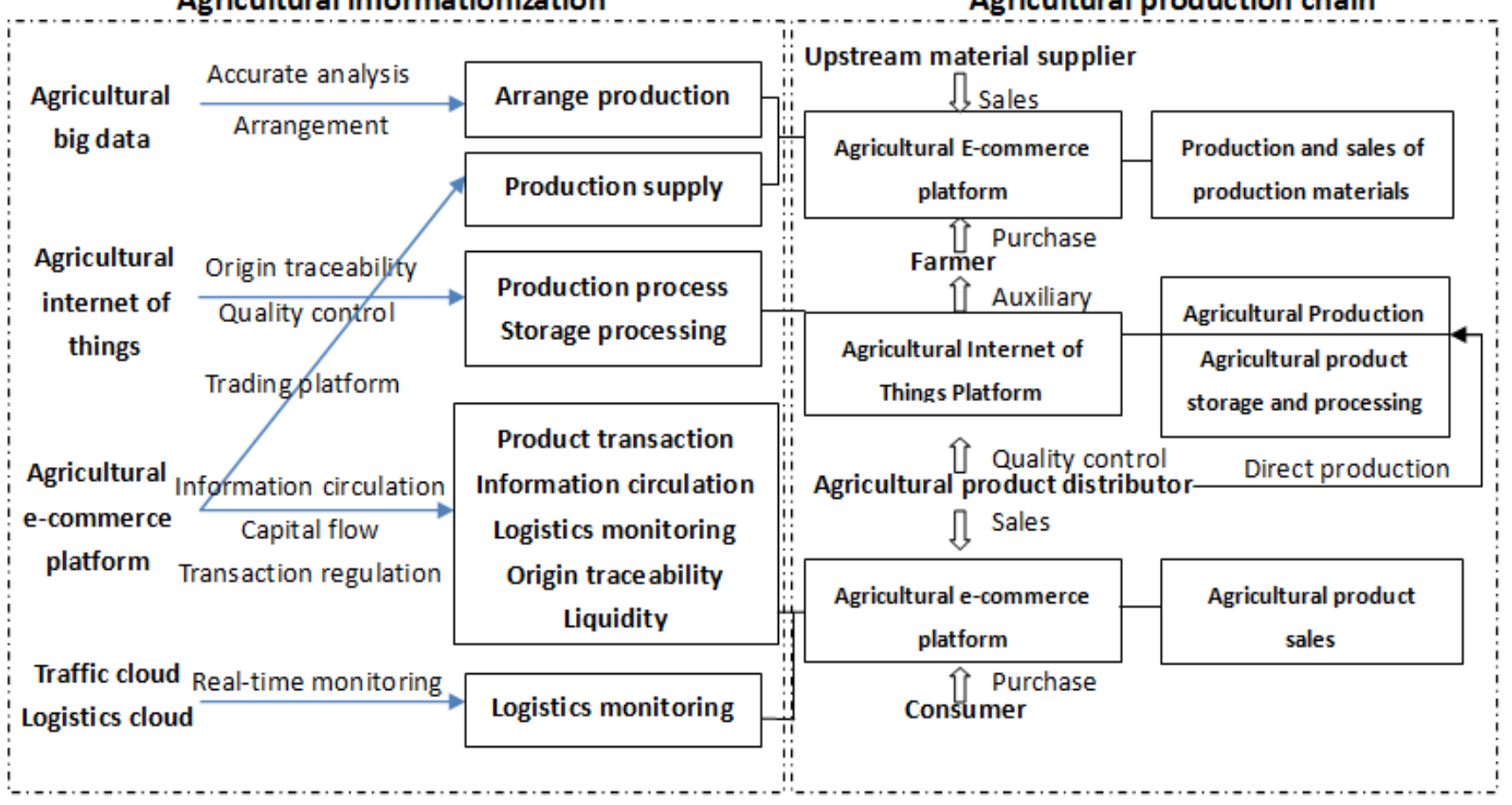

Fig. 1. Rural e-commerce reconstruction of the agricultural production chain based on information technology (schematic diagram)

After the reconstruction of the agricultural industrial chain, farmers have basic requirements for the use of information technology, which requires farmers to have information literacy and the ability of network and mobile terminals. According to the survey, the Internet penetration rate in rural areas of China was $33.1 \%$ in 2016 . However, farmers generally have a low cultural level, insufficient understanding of the Internet economy and lack of Internet thinking.

In order to make farmers become participants of agricultural e-commerce in the short term, it is necessary to break down the psychological barriers of farmers and realize "connecting to the net" and "touching the net". Taking Guizhou Post Office and Poverty Alleviation Office as an example, relying on the advantages of postal logistics Infiltration Township and cooperating with the township and village governments, the WeChat official account and the e-commerce shopping platform are used to popularize Guizhou goods to the whole country after collecting agricultural products directly from the producing area. Local farmers have poor informatization foundation and strong exclusion psychology for direct participation in e-commerce, but agricultural production is their own good work. Therefore, according to the overall arrangement, under the leadership of the grass-roots government, professionals arrange the production and marketing docking of agricultural products on and off the line, such as packaging, marketing, promotion, trading, logistics and quality assurance. Farmers are responsible for agricultural production under unified technical supervision. Only when farmers get tangible benefits can they spontaneously become a member of the information-based agricultural industry chain.

In the long run, it is necessary for Chinese farmers, like the new farmers in intelligent agricultural developed countries such as the United States and Israel, to master agricultural information technology to ensure the standard, quality and security of product production, and to make good use of e-commerce platform to realize the smooth flow of product output and information, as well as the multi-channel sales, etc.

The improvement of farmers' informatization level and the construction of agricultural informatization need the linkage of government, school, line and enterprise. The government formulates the agricultural information development strategy, the Internet infrastructure construction, the logistics base construction, the big data and the cloud base construction, the platform level e-commerce cooperation project introduction, the e-commerce professional incubation base construction, etc.

Platform level e-commerce cooperates with the government, which can assist local governments to establish rural e-commerce channels, ecological agricultural e-commerce supply chain system, rural e-commerce public support system, brand building, agricultural services, Internet financial system, modern logistics system. It also carries out precise poverty alleviation based on "agricultural products + platforms" and builds regional rural e-commerce system.

Colleges and universities should give full play to their scientific research advantages and social service functions, train smart agricultural innovators and entrepreneurs, carry out training in agricultural informatization technology and e-commerce at the grass-roots level, and create new agricultural informatization farmers. It also conducts scientific research and application for variety adjustment and capacity improvement, assists the government in brand building and production standards formulation provides precise poverty alleviation technology support and strategic support to the poor 
areas, and provides decision-making basis for the government to formulate policies.

\section{The CONSTRUCtion OF "INTERNET Plus" RuRAL E-COMMERCE INFORMATION SYSTEM MODEL}

As shown in the following figure, this work proposed an information construction system model based on the Internet perspective of rural e-commerce business flow, information flow, logistics and capital flow. In terms of pattern, taking the "four streams" of rural e-commerce as the core, the construction work is carried out from two aspects: the information infrastructure construction and the development direction of "Internet Pius" rural e-commerce informatization.

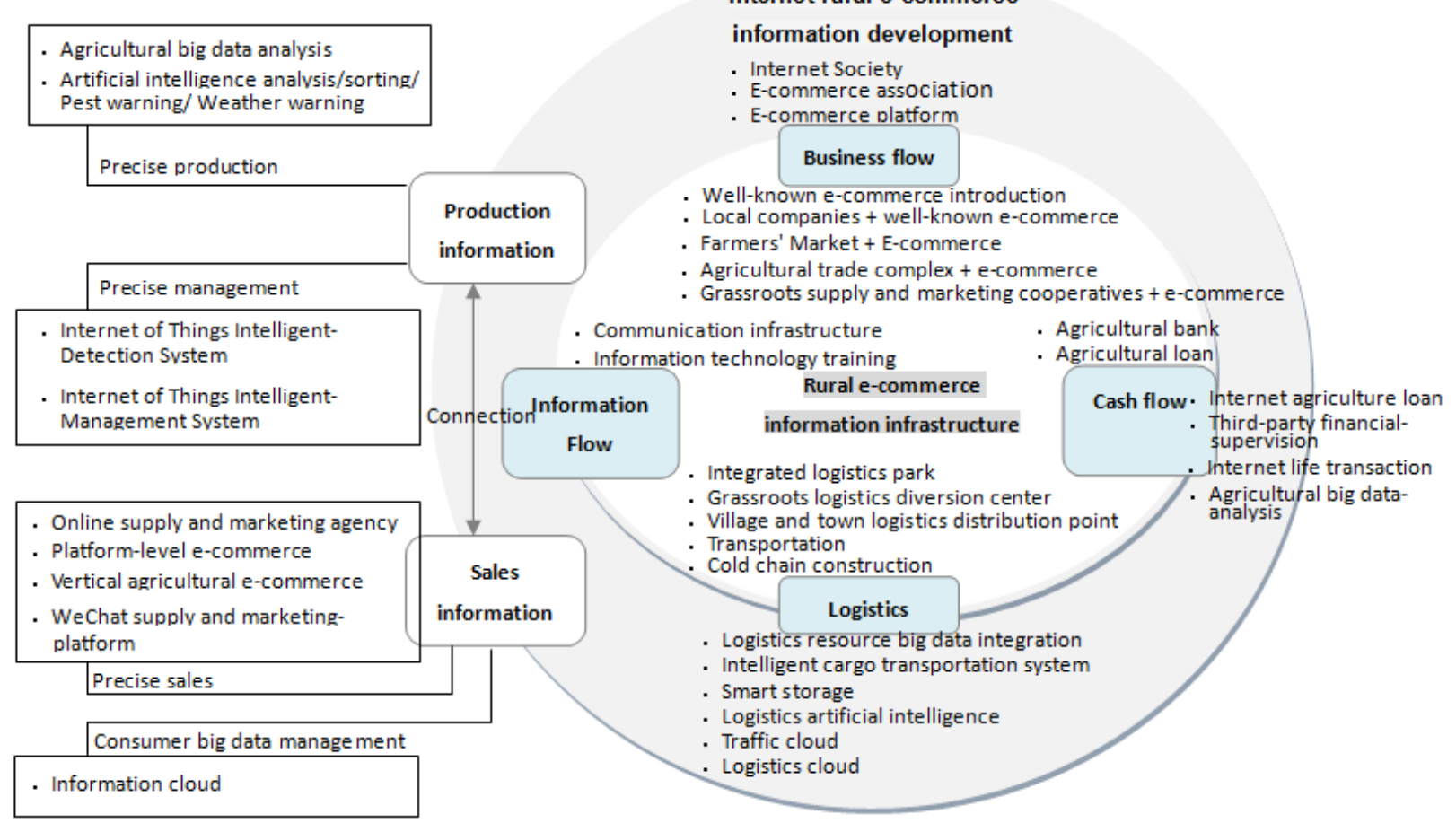

Fig. 2. "Internet Plus" rural e-commerce informatization model

\section{A. Information infrastructure construction}

In terms of business flow, it should speed up the introduction of well-known e-commerce, strengthen the integration of local enterprises, large-scale agricultural markets, large-scale commercial complexes and grass-roots supply and marketing cooperatives in villages and towns, cooperatives and e-commerce. The advantages of large-scale platform management and sales drive the transformation of entities, realize ideological transformation, online and offline transformation, disorderly to orderly transformation, take the road of cooperative operation and management, and realize multi-channel and wide-range circulation of agricultural products.

In terms of information flow, efforts should be made to develop Internet infrastructures such as communication infrastructure and network coverage. It covers urban and rural areas with 3G, 4G network, optical fiber broadband and wireless local area network. By December 2018, the number of non-netizens in rural areas was 562 million, accounting for $63.2 \%$ [3]. It is an important part of infrastructure construction to improve the environment of information facilities and to improve the level of farmers' information skills and culture.
In terms of logistics, it should build a multi-layer structure, network structure and terminal transportation system of large-scale logistics comprehensive park + grass-roots logistics distribution center + village and town logistics distribution network. Highway, railway, shipping, water transportation and other transport infrastructure is a prerequisite to ensure smooth logistics. The construction of cold chain facilities is an important concern of rural e-commerce. According to the actual situation, it can take self-built warehousing transportation or cooperate with platform e-commerce cold chain.

In terms of capital flow, Rural agricultural banks and postal banks should be built, and small agricultural loans should be carried out to facilitate capital flow in a way that farmers are familiar with and trust. With the process of farmers touching the network and connecting to the network, the Internet financial platform is further introduced.

\section{B. The construction of "Internet Plus" rural e-commerce informatization}

In terms of business flow, platform level e-commerce is introduced. Resources are integrated, and rural e-commerce platform is built in combination with local production. For example, the government-led online supply and marketing cooperatives, online cooperatives or local characteristic 
e-commerce online marketing platform, as well as well-known e-commerce platform to build a local characteristic library, create a characteristic brand image, expand the market radius. The establishment of Internet association, rural e-commerce association/alliance, it is necessary to focus on local rural economic development, condense government, industry and enterprises, maintain market order, standardize operational standards, and promote the characteristics, standardization, industrialization, and modernization of rural e-commerce.

In terms of information flow, production information and sales information are docked to achieve precise production, precise management and accurate sales. Agricultural big data is used to accurately analyze the market demand, planting/breeding distribution, listing time, weather change, harvest forecast, production capacity and other related information, and predict the sales prospect. Reasonable industrial distribution should be carried out according to the actual situation, so as to avoid the obstruction of agricultural product sales caused by excessive capacity, improper industrial distribution, the change of supply-demand relationship, climate change and many other factors from the source. The intelligent identification system of "artificial intelligence + agriculture" is used to detect soil condition, sorting seeds, image recognition technology to detect diseases and insect pests, health status of poultry and livestock, climate disaster early warning, etc., and make correct prediction and monitoring from the first chain of production link to realize accurate production. The intelligent detection system of agricultural IOT and intelligent control system make the production from traditional dependence on manual experience to intelligent agricultural precision management. It has the characteristics of copying and promotion, saving labor costs, significantly improving management scope and accurate data query and traceability. In the process of production, information such as production environment data, production process data, storage processing data, product traceability data, etc., are stored and fed back. Users can real-time detect, intelligent control and remote monitor crops at any time through various mobile terminals, thus realizing the visualization, controllability and traceability of production process information. It can provide first-hand information for sales and avoid food safety problems.

In the sales process, multi-level e-commerce platforms can be adopted for different consumer groups, and online supply and marketing cooperatives and vertical agricultural e-commerce companies are more oriented to the mass production needs of product processing enterprises. Platform level e-commerce and WeChat supply and marketing platforms have a wider impact on urban consumers. Through the e-commerce platform at all levels, the product information and logistics information are better transmitted to all kinds of consumers. The consumption of big data is accurately analyzed through the information cloud, and the consumer groups, regions and fields of agricultural products are judged. It analyses the concerns and demand information of various consumers, provides reference and basis for follow-up production, docks production and marketing information, and realizes precise sales for different consumer groups.

In terms of logistics flow, through big data's integration of scattered logistics resources, intelligent cargo transportation and storage system shall be established, and artificial intelligence shall be adopted to control logistics robot for express delivery sorting and packaging, so as to reduce labor costs and improve sorting efficiency [4]. It analyzes traffic congestion, releases traffic information, conducts route selection and travel guidance, reasonably dispatches vehicles and grasps the trend of vehicles through the traffic cloud. Combining with logistics cloud, information control of logistics links is carried out. Express company, delivery point, vehicle information and other terminals are managed systematically under the unified platform, and logistics work is carried out efficiently, accurately and safely.

In terms of capital flow, new Internet financial platforms are introduced as a beneficial supplement to the agricultural economy, through which agricultural loan services and financial services are carried out, and third-party financial supervision platforms are adopted to supervise capital flow to ensure the safety of funds between buyers and sellers. Financial big data analysis can effectively connect the capital demand end with the capital supply end, evaluate the management ability, repayment ability, credit record and stability degree of the core enterprises, farmers and other objects, and play a very important role in the stability of the whole agricultural economy [5]. It is worth mentioning that the demand for living materials in rural areas is also increasing day by day. The use of Internet life trading platform can effectively meet the needs of farmers' friends to buy tickets, travel and so on, and become a new growth point of rural e-commerce wealth.

\section{CONCLUSION}

"Internet + agriculture" integrates agricultural technology system and rural information service system, dabbles in a wide range, and has the characteristics of intelligence, material integration, perception, real-time and so on [6]. It is widely used in many fields, such as agricultural product e-commerce, agricultural finance, agricultural precision management, agricultural information service, etc., which stretch across the primary, secondary and tertiary industries. Rural e-commerce with the new information technology as the core has opened up the whole chain of the agricultural production chain. The rural informatization construction model under the Internet perspective puts forward the main work (informatization construction) around the "four streams" of e-commerce, and puts forward the operable implementation plan for precise poverty alleviation.

\section{REFERENCES}

[1] Guan Xihua. Building Agricultural Industry Bank with Agricultural Supply Chain Finance [J]. People's Forum, 2011, (9)

[2] Chen Lin. Strategic Research on Agricultural E-commerce Promoting Rural Information Technology Development [J]. Agricultural Network Information, 2015, (1)

[3] China Internet Information Center. 43rd China Internet Development Statistics Report [R]. Beijing: China Internet Information Center, 2019.

[4] Sohu. Talking about Nine Intelligent Logistics Robots [EB/OL] http://www.sohu.com/a/285308443_120059788, 2018-12-28. 
[5] Li Jianying, Wang Yuchen. Advantages, Difficulties and Optimizing Measures of Rural Internet Finance Development in Hebei Province [J]. Hebei Finance, 2016, (10)

[6] Xinhua net. "Internet plus" has Far-reaching Influence on China's Agricultural Modernization.
[EB/OL].

http://m.haiwainet.cn/middle/457130/2015/0520/content_28754191_1.ht $\mathrm{ml}, 2015-5-20$ 